\title{
The Relationship of Sexual Abuse with Self-Esteem, Depression, and Problematic Internet Use in Korean Adolescents
}

\author{
Bung-Nyun Kim¹, Subin Park ${ }^{2}$, and Min-Hyeon Park ${ }^{3}$ \\ ${ }^{1}$ Department of Psychiatry and Behavioral Science, Seoul National University College of Medicine, Seoul, Republic of Korea \\ ${ }^{2}$ Department of Research and Planning, Mental Health Research Institute, National Center for Mental Health, Seoul, Republic of Korea \\ ${ }^{3}$ Department of Psychiatry, The Catholic University of Korea, Seoul St. Mary's Hospital, Seoul, Republic of Korea
}

\begin{abstract}
The association of sexual victimization with self-esteem, depression, and problematic internet use was examined in Korean adolescents. A total of 695 middle and high school students were recruited (413 boys, 282 girls, mean age, $14.06 \pm 1.37$ years). The participants were administered the Early Trauma Inventory Self Report-Short Form (ETISR-SF), Rosenberg's Self-Esteem Scale (RSES), the Children's Depression Inventory (CDI), and Young's Internet Addiction Test (IAT). The associations between sexual abuse and the level of self-esteem, depressive symptoms, and problematic internet use were analyzed. Adolescents who had experienced sexual abuse showed lower self-esteem, more depressive symptoms, and greater problematic internet use compared with adolescents who had not experienced sexual abuse. In the path model, sexual abuse predicted lower self-esteem $(\beta=-0.11 ; 95 \% \mathrm{CI}=-0.20,-0.04 ; \mathrm{p}=0.009)$, which predicted higher depressive symptoms $(\beta=-0.34 ; 95 \% \mathrm{CI}=-0.40,-0.27 ; \mathrm{p}=0.008)$. Depressive symptoms predicted problematic internet use in a positive way $(\beta=0.23 ; 95 \% \mathrm{CI}=0.16-0.29 ; \mathrm{p}=0.013)$. Sexual abuse also predicted problematic internet use directly $(\beta=0.20 ; 95 \% \mathrm{CI}=0.12-0.27$; $\mathrm{p}=0.012$ ). The results of the present study indicate that sexually abused adolescents had a higher risk of depression and problematic internet use. For sexually abused adolescents, programs aimed at raising self-esteem and preventing internet addiction, as well as mental health screening, are needed.

Psychiatry Investig 2017;14(3):372-375
\end{abstract}

Key Words Sexual abuse, Problematic internet use, Self-esteem, Depression.

\section{INTRODUCTION}

Child victimization including childhood sexual abuse (CSA) is an important etiological factor in the development of several psychiatric disorders or symptoms in both childhood and adulthood. ${ }^{1}$ Among adolescents, commonly reported sequelae include sexual dissatisfaction, promiscuity, and an increased risk of revictimization. Depression and suicidal behavior or ideation are more common in sexually abused adolescents compared to normal and psychiatric nonabused controls. ${ }^{2}$

A mechanism that may help to explain the distress of sexually abused children is the potential damage to self-concept, leading to a proliferation of negative self-evaluations and neg-

Received: December 21, 2015 Revised: April 9, 2016

Accepted: May 23, 2016 Available online: January 10, 2017

$\triangle$ Correspondence: Subin Park, MD, PhD

Department of Research and Planning, Mental Health Research Institute, National Center for Mental Health, 127 Yongmasan-ro, Gwangin-gu, Seoul 04933, Republic of Korea

Tel: +82-2-2204-0108, Fax: +82-2-2204-0280, E-mail: subin-21@hanmail.net

(c) This is an Open Access article distributed under the terms of the Creative Commons Attribution Non-Commercial License (http://creativecommons.org/licenses/by$\mathrm{nc} / 4.0$ ) which permits unrestricted non-commercial use, distribution, and reproduction in any medium, provided the original work is properly cited. ative core beliefs, including a sense of inferiority and low selfefficacy., Many studies have demonstrated an association between sexual abuse and low self-esteem in children. ${ }^{5,6}$ Given that declines in self-esteem may be direct outcomes of sexual victimization, self-esteem may represent mediators between sexual victimization exposure and mental health outcomes.

Problematic internet use is characterized by an individual's inability to control his/her use of the internet resulting in marked distress and/or functional impairment. ${ }^{7}$ In previous studies, problematic internet use was encountered in approximately $10-30 \%$ of Korean junior or senior high school students, ${ }^{7-10}$ and highly associated with adolescent depression. $^{7-9,11-13}$ Several studies mentioned that lower self-esteem triggers excessive internet use ${ }^{14,15}$ and a significant correlation emerged between depression, self-esteem, and internet addiction. ${ }^{16,17}$

Although both the association between sexual victimization and self-esteem and depression and the association between self-esteem, depression, and problematic internet use have been confirmed by previous studies, the direct association between sexual victimization and problematic internet 
use has not been examined. In this respect, this study examined the association of sexual victimization with self-esteem, depression, and problematic internet use in Korean adolescents. Based on the previous reports of the adverse effects of sexual victimization on self-esteem and depression, ${ }^{18}$ which are associated with problematic internet use, ${ }^{16,17}$ it was hypothesized that 1) sexual victimization is related to problematic internet use and 2) this tentative association is partially mediated by a decline in self-esteem and increased depressive symptoms.

\section{METHODS}

\section{Participants}

A total of 802 students ( 413 boys, 282 girls) between the 7 th and 11th grade (mean age, $14.06 \pm 1.37$ years) were recruited from one junior high school and one senior high school that were located in Seoul, Korea. These schools volunteered to participate in this study. After the school principals approved the research, the investigators visited the schools, explained the purpose of the study to the students and teachers, obtained consent from the students, and distributed and collected the questionnaires. The authors also mailed letters to parents that outlined the study's objectives, guaranteed confidentiality, provided a contact telephone number for the principal investigator and indicated that parents would be informed of the results after the analyses were completed. The letter also included a statement that parents were free to refuse to respond if they did not agree with the study's objective. This study was approved by the human subjects Institutional Review Board (IRB) (No. C-1412-081-633) at Seoul National University Hospital.

\section{Measures}

\section{The Early Trauma Inventory Self Report-Short Form}

The ETISR-SF is a 27-item questionnaire used for the assessment of physical abuse, emotional abuse, sexual abuse, and general traumatic experience that may have occurred before age 18. The measure has been shown to have excellent validity and internal consistency. ${ }^{19,20}$ Sexual abuse was defined as unwanted sexual comments or contact performed solely for the gratification of the perpetrator or for the purposes of dominating or degrading the victim, and was assessed by six corresponding items. Each traumatic experience was scored dichotomously (yes $=1 /$ no $=0$ ). Subjects who experienced any sexual abuse were placed in the sexually abused group, and subjects who did not experience such an event were placed in the nonabused group.

\section{Rosenberg's Self-Esteem Scale}

RSES is a widely used self-report instrument that measures global self-worth. It has ten items. Participants answer each item on a 5-point Likert scale, ranging from 1 (strongly disagree) to 5 (strongly agree). The total score ranges from 10 to $50 . .^{21,22}$

\section{The Children's Depression Inventory}

The CDI is a 27-item, self-rated, symptom-oriented scale that is suitable for youth aged 7 to 17 . Each CDI item consists of three statements that are rated on a scale that ranges from $0-2$. The total score ranges from 0 to $54 .^{23,24}$

\section{Young's Internet Addiction Test}

IAT, developed for screening and measuring levels of internet addiction, is a 20 -item questionnaire that uses a five-point Likert Scale. In the IAT, internet-related behavioral problems and psychological distress problems are covered. An IAT score of 50 to 79 is regarded as a mild degree of internet addiction (i.e., occasional problems with internet use). A score of 80 or greater is regarded as a severe degree of internet addiction (i.e., having significant problems in daily life). ${ }^{25,26} \mathrm{~A}$ higher score indicates a greater level of addiction. The total score ranges from 20 to 100 .

\section{Statistical analyses}

We compared the characteristics of the sexually abused group and the non-abused group using independent t-tests for continuous variables and the chi-squared test for categorical variables. SPSS (version 21.0; SPSS, Inc., Chicago, IL, USA) was used to perform all statistical analyses. We also used AMOS (version 19.0; SPSS Inc., Chicago, IL, USA) to conduct path analyses. Sexual abuse state, the RSES scores, CDI scores, and IAT scores were included in the path model. A p-value less than 0.05 was considered significant.

\section{RESULTS}

Of the 802 students initially recruited in the study, 107 were excluded due to incomplete responses, which resulted in 695 subjects ( 413 boys, 282 girls, mean age, 14.06 \pm 1.37 years). Table 1 shows the group-specific demographic and clinical characteristics. There were no significant differences in age, sex, parental educational levels, and family income between the groups. The sexually abused group showed lower RSES ( $\mathrm{t}=$ -3.04, $\mathrm{p}=0.002)$, higher CDI $(\mathrm{t}=2.22, \mathrm{p}=0.027)$, and higher IAT $(\mathrm{t}=5.99, \mathrm{p}<0.001)$ scores compared with those in the nonabused group.

In the path model, sexual abuse predicted lower self-esteem $(\beta=-0.11 ; 95 \% \mathrm{CI}=-0.20,-0.04 ; \mathrm{p}=0.009)$, which predicted 
Table 1. Characteristics of study participants

\begin{tabular}{|c|c|c|c|c|}
\hline Characteristics & $\begin{array}{c}\text { Adolescents with } \\
\text { sexual abuse }(\mathrm{N}=59)\end{array}$ & $\begin{array}{c}\text { Adolescents without } \\
\text { sexual abuse }(\mathrm{N}=636)\end{array}$ & $\chi^{2} / t$ & $\mathrm{p}$ \\
\hline Sex, N (\%) & $42(71.2)$ & $371(58.3)$ & 3.70 & 0.054 \\
\hline Age, mean (SD) & $14.25(1.45)$ & $14.04(1.36)$ & 1.16 & 0.248 \\
\hline Paternal education level (\%) & & & 0.26 & 0.880 \\
\hline Middle school or below & 7.4 & 5.2 & & \\
\hline High school & 37.0 & 36.9 & & \\
\hline College or above & 55.6 & 57.9 & & \\
\hline Maternal educational level (\%) & & & 0.06 & 0.969 \\
\hline Middle school or below & 6.7 & 5.6 & & \\
\hline High school & 50.0 & 50.0 & & \\
\hline College or above & 43.3 & 44.4 & & \\
\hline Family income, N (\%) & & & 1.27 & 0.529 \\
\hline Below 2,000,000 & $\mathrm{N}(23.3)$ & $\mathrm{N}(19.1)$ & & \\
\hline $2,000,000-5,000,000$ & $\mathrm{~N}(43.3)$ & $\mathrm{N}(54.0)$ & & \\
\hline Above $5,000,000$ & $\mathrm{~N}(33.3)$ & $\mathrm{N}(26.9)$ & & \\
\hline Rosenberg's self-esteem scale, mean (SD) & $27.64(6.93)$ & $30.23(6.20)$ & -3.04 & 0.002 \\
\hline Children's Depression Inventory, mean (SD) & $17.03(6.27)$ & $14.92(7.06)$ & 2.22 & 0.027 \\
\hline Young's Internet Addiction Test, mean (SD) & $44.14(16.38)$ & $32.74(12.62)$ & 5.99 & $<0.001$ \\
\hline
\end{tabular}

higher depressive symptoms $(\beta=-0.34 ; 95 \% \mathrm{CI}=-0.40,-0.27$; $\mathrm{p}=0.008)$. Depressive symptoms predicted problematic internet use in a positive way $(\beta=0.23 ; 95 \% \mathrm{CI}=0.16-0.29, \mathrm{p}=0.013)$. Sexual abuse also predicted problematic internet use directly $(\beta=0.20 ; 95 \% \mathrm{CI}=0.12-0.27 ; \mathrm{p}=0.012)$. The path model showed an excellent fit to the data $(\mathrm{GFI}=0.999, \mathrm{AGFI}=0.994, \mathrm{CFI}>0.99$, RMSEA $<0.001$, chi-square $=1.80$ and chi-square $p$-value $=0.406$ ) (Figure 1).

\section{DISCUSSION}

The primary goal of this study was to investigate the relationship of sexual victimization with self-esteem, depressive symptoms, and problematic internet use in Korean adolescents. Our findings indicate a significant association between sexual victimization and problematic internet use, which is partially mediated by low self-esteem and increased depressive symptoms.

The observed association between sexual victimization, lower self-esteem, and depression is consistent with previous studies. ${ }^{25,6}$ Turner et al. ${ }^{18}$ reported that sexual victimization independently reduced self-esteem and that declines in self-esteem partially mediated the association between past-year sexual victimization exposure and levels of depressive symptoms. In our path model, lower self-esteem fully mediated the association between sexual victimization and depressive symptoms.

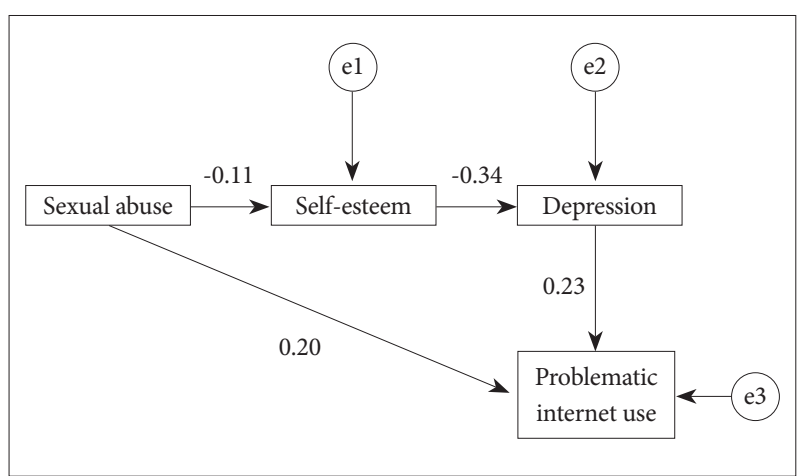

Figure 1. Path analysis showing associations between sexual abuse, self-esteem, depressive symptoms, and problematic internet use in adolescents. Sexual abuse predicts problematic internet use both directly and indirectly via mediation by lower self-esteem and higher depressive symptoms. Only significant paths are presented.

In addition to such a well-known relationship, we found that sexual victimization was associated with problematic internet use in adolescents. The mean IAT score for the sexually abused group indicates a mild degree of internet addiction (i.e., occasional problems with internet use), while the score for the non-abused group indicates average internet users (i.e., having no problems with internet use). Consistent with our hypothesis, this association was partially mediated by low self-esteem and high depressive symptoms. However, even after excluding the mediating effect of self-esteem and depressive symptoms, there was a significant association between sexual victimization and problematic internet use. Childhood 
sexual abuse may lead to maladaptive coping skills, disturbed self-identity, poor interpersonal skills, and lack of intimacy, as well as low self-esteem. ${ }^{27,28}$ According to the social learning theory postulated by Bandura, ${ }^{29}$ low self-efficacy and poor coping strategies elicit the risk of developing addictions to cope. Cognitive-behaviorists also suggest that disruption in the areas of identity formation and developing meaningful relationships or intimacy may lead the individual to use the internet as a means of escape and emotional numbing or fulfilling developmental intimacy needs. ${ }^{30}$ Therefore, such a variety of correlates or mediators should be examined to identify the true relationship between sexual victimization and problematic internet use in future studies.

Our study had several limitations. First, due to the subjects being asked to recall trauma that they experienced in the past, the respondents' reports may be characterized by inaccuracies. Second, this study was cross-sectional; thus, we could not identify causal relationships between sexual victimization, self-esteem, depressive symptoms, and problematic internet use. Finally, the schools volunteered to participate in the study. Therefore, our findings may not be representative of all Korean adolescents and future studies should include larger, more representative samples.

The results of the present study indicate that adolescents who experienced sexual abuse are at greater risk of depression and problematic internet use. A clinical implication of this study is that treatment for adolescents who experienced sexual abuse should include mental health screening, interventions to raise self-esteem, and internet addiction prevention programs. Future prospective studies are needed to further clarify the causal relationships among childhood sexual abuse, depression, and problematic internet use.

\section{Acknowledgments}

This work was supported by the National Research Foundation of Korea (NRF) Grant funded by the Korean Government (MSIP) (NRF2014R1A1A3049818).

\section{REFERENCES}

1. Green AH. Child sexual abuse: immediate and long-term effects and intervention. J Am Acad Child Adolesc Psychiatry 1993;32:890-902.

2. Beitchman JH, Zucker KJ, Hood JE, daCosta GA, Akman D. A review of the short-term effects of child sexual abuse. Child Abuse Negl 1991;15: 537-556.

3. Finkelhor D, Browne A. The traumatic impact of child sexual abuse: a conceptualization. Am J Orthopsychiatry 1985;55:530-541.

4. Gibb BE. Childhood maltreatment and negative cognitive styles. A quantitative and qualitative review. Clin Psychol Rev 2002;22:223-246.

5. Feiring C, Taska L, Lewis M. Adjustment following sexual abuse discovery: the role of shame and attributional style. Dev Psychol 2002;38: 79-92.

6. Stern AE, Lynch DL, Oates RK, O’Toole BI, Cooney G. Self esteem, depression, behaviour and family functioning in sexually abused children. J Child Psychol Psychiatry 1995;36:1077-1089.

7. Park S, Hong KEM, Park EJ, Ha KS, Yoo HJ. The association between problematic internet use and depression, suicidal ideation and bipolar disorder symptoms in Korean adolescents. Aust N Z J Psychiatry 2013; 47:153-159.

8. Ha JH, Kim SY, Bae SC, Bae S, Kim H, Sim M, et al. Depression and internet addiction in adolescents. Psychopathology 2007;40:424-430.

9. Jang KS, Hwang SY, Choi JY. Internet addiction and psychiatric symptoms among Korean adolescents. J Sch Health 2008;78:165-171.

10. Yoo HJ, Cho SC, Ha J, Yune SK, Kim SJ, Hwang J, et al. Attention deficit hyperactivity symptoms and internet addiction. Psychiatry Clin Neurosci 2004;58:487-494.

11. Fu KW, Chan WS, Wong PW, Yip PS. Internet addiction: prevalence, discriminant validity and correlates among adolescents in Hong Kong. Br J Psychiatry 2016;196:486-492.

12. Kim K, Ryu E, Chon MY, Yeun EJ, Choi SY, Seo JS, et al. Internet addiction in Korean adolescents and its relation to depression and suicidal ideation: a questionnaire survey. Int J Nurs Stud 2006;43:185-192.

13. Williamson D, Dewey A, Steinberg H. Mood change through physical exercise in nine- to ten-year-old children. Percept Mot Skills 2001;93: 311-316.

14. Greenberg JL, Lewis SE, Dodd DK. Overlapping addictions and self-esteem among college men and women. Addict Behav 1999;24:565-571.

15. Murali V, George S. Lost online: an oveview of internet addiction. Adv Psychiatr Treat 2007;13:24-30.

16. Bahrainian SA, Alizadeh KH, Raeisoon MR, Gorji OH, Khazaee A. Relationship of internet addiction with self-esteem and depression in university students. J Prev Med Hyg 2014;55:86-89.

17. Senormanci O, Saracli O, Atasoy N, Senormanci G, Kokturk F, Atik L. Relationship of Internet addiction with cognitive style, personality, and depression in university students. Compr Psychiatry 2014;55:1385-1390.

18. Turner HA, Finkelhor D, Ormrod R. The effects of adolescent victimization on self-concept and depressive symptoms. Child Maltreat 2010; 15:76-90.

19. Bremner JD, Bolus R, Mayer EA. Psychometric properties of the Early Trauma Inventory-Self Report. J Nerv Ment Dis 2007;195:211-218.

20. Cho MJ, Kim JK, Jeon HJ, Suh T, Chung IW, Hong JP, et al. Lifetime and 12-month prevalence of DSM-IV psychiatric disorders among Korean adults. J Nerv Ment Dis 2007;195:203-210.

21. Jeon BJ. Self-esteem: a test of its measurability. Yonsei Nonchong 1974; 11:107-129.

22. Rosenberg M. Society and Adolescent Self-Image. Princeton, NJ: Princeton University Press; 1965.

23. Kovacs M. The Children's Depression Inventory: A Self-rated Depression Scale for School-aged Youngsters. Unpublished manuscript, University of Pittsburgh; 1983.

24. Cho SC, Yi YS. Development of the Korean form of the Kovacs' Children's Depression Inventory. J Korean Neuropsychiatr Assoc 1990;29: 943-956.

25. Ha JH, Yoo HJ, Cho IH, Chin B, Shin D, Kim JH. Psychiatric comorbidity assessed in Korean children and adolescents who screen positive for Internet addiction. J Clin Psychiatry 2006;67:821-826.

26. Young KS. Caught in the Net. New York: John Wiley \& Sons; 1998.

27. Wilson DR. Health consequences of childhood sexual abuse. Perspect Psychiatr Care 2010;46:56-64.

28. Trickett PK, Noll JG, Putnam FW. The impact of sexual abuse on female development: lessons from a multigenerational, longitudinal research study. Dev Psychopathol 2011;23:453-476.

29. Bandura A. Self-Efficacy: The Exercise of Control. New York: Freeman; 1997.

30. Davis RA. A cognitive-behavioral model of pathological internet use. Comput Human Behav 2001;17:187-195. 